\title{
Analysis of Catalytic Material Effect on the Photovoltaic Properties of Monolithic Dye-sensitized Solar Cells
}

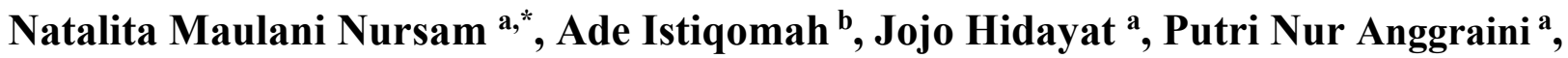 \\ Shobih ${ }^{\text {a }}$ \\ ${ }^{a}$ Research Center for Electronics and Telecommunication, Indonesian Institute of Sciences (P2ET-LIPI) \\ Komplek LIPI Gedung 20 lantai 4, Jl Sangkuriang Cisitu, Bandung 40135, Indonesia \\ ${ }^{b}$ Department of Physics Engineering, Telkom University \\ Jl. Telekomunikasi No. 1, Terusan Buah Batu, Sukapura, Dayeuh Kolot, Bandung 40257, Indonesia
}

\begin{abstract}
Dye-sensitized solar cells (DSSC) are widely developed due to their attractive appearance and simple fabrication processes. One of the challenges that arise in the DSSC fabrication involves high material cost associated with the cost of conductive substrate. DSSC with monolithic configuration was then developed on the basis of this motivation. In this contribution, titanium dioxide-based monolithic type DSSCs were fabricated on a single fluorine-doped transparent oxide coated glass using porous $\mathrm{ZrO}_{2}$ as spacer. Herein, the catalytic material for the counter-electrode was varied using carbon composite and platinum in order to analyze their effect on the solar cell efficiency. Four-point probe measurement revealed that the carbon composite exhibited slightly higher conductivity with a sheet resistance of $9.8 \Omega /$ sq and $10.9 \Omega /$ sq for carbon and platinum, respectively. Likewise, the photoconversion efficiency of the monolithic cells with carbon counter-electrode almost doubled the efficiency of the cells with platinum counter-electrode. Our results demonstrate that carbon could outperform the performance of platinum as catalytic material in monolithic DSSC.
\end{abstract}

Keywords: carbon, counter-electrode, dye-sensitized, photovoltaic, platinum, solar cell.

\section{INTRODUCTION}

Although solar energy arguably holds great potential as it is abundant enough to fulfill the whole world total energy demand, the high market cost associated with the photovoltaic devices is often become a major hurdle. Dye-sensitized solar cell (DSSC) provides solution for this issue. DSSC is basically part of third generation solar cell family that equipped with several advantages, such as low production cost, shorter investment payback time, colorful appearance, and transparency [1].

Since its initial report by Graetzel in 1991 [2], the photoconversion efficiency of DSSC has now been propelled over $10 \%$ [3]. However, since the efficiency of DSSC still struggles to compete with the recorded high efficiencies of silicon-based solar cells, many attempts have been developed to increase its selling point, for instance, by further reducing the material cost.

In a conventional DSSC, two transparent conducting oxide (TCO) substrates are typically used to serve as working- and counter-electrode. This scheme is often referred as a "sandwich" structure. The use of TCO is considered necessary because it has high electrical conductivity that is required to transfer the charge carrier between the solar cell and the external loads. In addition, transparent TCO glasses are necessary to allow unobstructed light penetration into the internal parts of the solar cell. However, the use of

\footnotetext{
* Corresponding Author.

Email: natalita.maulani.nursam@lipi.go.id

Received: August 18, 2017 ; Revised: September 13, 2017

Accepted: September 14, 2017 ; Published: December 30, 2017

(C) 2017 PPET - LIPI
}

TCO glasses significantly increases the cost of DSSC as it contributes to at least $60 \%$ of the material cost [4]. Much efforts therefore has been conducted to either eliminate or reduce the use of TCO substrate in DSSC. In our previous work, for example, we reported the deposition method of platinum on TCO-free substrate through pre-etching step in hydrofluoric acid solution [5]. Kuang et al. replaced TCO with poly(3,4-ethylene dioxythiophene) coupled with poly(styrene sulfonate) or PEDOT:PSS film as conductive substrate [6]. Other conductive polymers such as polyaniline [7], polypyrrole [8], polythiophene [9], etc have also been reported as potential alternatives for TCO substrate. Although they are considered as promising emerging materials, the conductivity and cost of those materials did not really give much leverage against TCO.

Rather than completely removing the use of both $\mathrm{TCO}$, an alternative way is to eliminate one of the TCO substrates. By using monolithic configuration, a single TCO substrate can be used to serve as both workingand counter-electrode. This can be made possible by removing some of the conductive layer on the substrate in order to isolate the anode and cathode. The challenges that arise from such scheme is typically related to the spacer and counter-electrode material. Previous study showed that the thickness of both spacer and counter-electrode materials have significant effects on the performance of monolithic DSSC [10]. The type of catalytic material on the counter-electrode, however, has not been specifically discussed.

In the present contribution, we aim to study the effects of counter-electrode materials on the photovoltaic performance of DSSC with monolithic 
structure. Platinum was selected as one of the materials of interest because it has been widely used as catalyst in conventional DSSCs. As a comparison, carbon based material was also used as counter-electrode because carbon is low-cost, abundant and its synthetic method has also been widely developed. Additionally, carbon is known to have good conductivity and reasonable catalytic activity [11]. The results of this study are expected to promote further development on the monolithic DSSC in the future.

\section{METHODOLOGY}

\section{A. Materials}

All chemicals were used as received without further modification. Fluorine-doped transparent oxide $\left(\mathrm{SnO}_{2}: \mathrm{F}\right)$ coated glasses or FTO with a conductivity of $\sim 15 \Omega /$ sq (TEC15), $\mathrm{TiO}_{2}$ opaque paste (18NR-AO), ruthenium based dye $\left[\mathrm{RuL}_{2}(\mathrm{NCS})_{2}\right]: 2$ tetra-nbutylammonium, where $\mathrm{L}=2,2$ '-bipyridil-4,4'dicarboxylic acid (Z907), ionic liquid electrolyte (ELHSE), platinum paste (PT1), and low temperature thermoplastic sealant (DuPont Surlyn ${ }^{\circledR}$ ) were purchased from Dyesol ${ }^{\mathrm{TM}}$ (recently re-named as Greatcell Solar), Australia. Meanwhile, the $\mathrm{ZrO}_{2}$ paste and carbon nanopowder was supplied by Solaronix and Aldrich, respectively. Colloidal graphite was purchased from Polaron Instruments Inc. Isopropyl alcohol and ethanol (both reagent grade) were obtained from Merck. Millipore water with resistivity higher than $15 \mathrm{M} \Omega$ was used throughout the experiments.

\section{B. Cell Fabrication}

First, FTO glass was scribed with diamond cutter to separate the designated anode and cathode side. The conductive glasses were then cleaned by ultrasonicating in detergent, deionized water, isopropyl alcohol, and ethanol, successively, for $10 \mathrm{~min}$ each. After being dried in air, $\mathrm{TiO}_{2}$ paste was printed on the conductive side of the FTO glass using de Haart SP SA 40 screen printer. The printing area was $1 \times 1 \mathrm{~cm}^{2}$. The deposition was carried out in two cycles, wherein the film was dried in an oven at $125^{\circ} \mathrm{C}$ for $10 \mathrm{~min}$ after each cycle. The films were subsequently annealed at $500{ }^{\circ} \mathrm{C}$ for $15 \mathrm{~min}$ in a conveyer belt furnace (Radiant Technology Corporation). The sintered films were then immersed in $40 \mathrm{mM}$ of $\mathrm{TiCl}_{4}$ aqueous solution at $70{ }^{\circ} \mathrm{C}$ for $30 \mathrm{~min}$ as a post-treatment, followed by another annealing under the same conditions as the $\mathrm{TiO}_{2}$ sintering. Next, porous $\mathrm{ZrO}_{2}$ paste was screen printed on top of the $\mathrm{TiO}_{2}$ layer with an area of $0.7 \times 1.1 \mathrm{~cm}^{2}$ and then sintered at $400{ }^{\circ} \mathrm{C}$ for $20 \mathrm{~min}$. The final thickness of the $\mathrm{TiO}_{2}$ and $\mathrm{ZrO}_{2}$ layer was $8 \mu \mathrm{m}$ and $2 \mu \mathrm{m}$, respectively.

The catalytic layer for the counter-electrode, either carbon or platinum, was subsequently deposited on top of the $\mathrm{TiO}_{2}$ and $\mathrm{ZrO}_{2}$ with a size of $1 \times 0.5 \mathrm{~cm}^{2}$. The carbon paste was prepared according to a recipe published elsewhere [10], i.e. carbon black (150 mg) was mixed thoroughly with graphite $(210 \mathrm{mg})$, P25 (310 $\mathrm{mg})$, acetic acid $(0.15 \mathrm{~mL})$, and deionized water $(2 \mathrm{~mL})$ in a mortar. Meanwhile, the platinum paste used was commercially purchased from Dyesol. The depositions of both carbon and platinum were conducted repeatedly to obtain catalytic layer with a thickness of approximately $10 \mu \mathrm{m}$. The coated samples were dried at $150{ }^{\circ} \mathrm{C}$ between each deposition. All samples were subsequently soaked in dye solution with a concentration of $20 \mathrm{mg} / \mathrm{L}$ overnight under dark condition to sensitize the $\mathrm{TiO}_{2}$ particles. After dried in air, the cells were then encapsulated with coverslips that were attached using thermoplastic sealant. Liquid electrolyte containing $\mathrm{I}_{3}^{-} / \mathrm{I}^{-}$redox mediators were immediately injected through the empty space allocated in the Surlyn, followed by sealing the hole with another piece of thermoplastic sealant.

\section{Characterizations}

Field emission scanning electron microscopy (FESEM) imaging using JEOL JB-4610F operated at $15 \mathrm{kV}$ and equipped with energy dispersive X-ray (EDX) was carried out to study the surface morphology of the samples. All samples were sputter coated with carbon prior to the SEM characterization. The crystal structure of the films were analyzed using X-ray diffraction (XRD) on Shimadzu Maxima XRD-7000 with $\mathrm{Cu} \mathrm{K \alpha}$ source at $\lambda=1.54 \AA$. Meanwhile, the conductivity of the catalytic films was measured using four-point probe (Alessi) with Hewlett-Packard 3468A multimeter and 6186C DC current source. Pre-annealed carbon or platinum films with an area of $1 \times 0.5 \mathrm{~cm}^{2}$ were deposited directly on top of FTO glass for the purpose of this measurement.

The photovoltaic properties of the cells were analyzed by measuring the current-voltage characteristics using National Instrument $I-V$ measurement system under simulated solar irradiation with AM1.5G filter and an intensity of $50 \mathrm{~mW} / \mathrm{cm}^{2}$. The measurements were conducted at room temperature under dark and illuminated condition. The active area of each cell was defined to be $0.5 \times 0.5 \mathrm{~cm}^{2}$.

\section{RESUlTS AND Discussion}

Figure 1 shows the comparison between the schematic structure of sandwich and monolithic DSSC device proposed in this work. From this figure, there are several distinct features that can be distinguished between both structures, i.e. (i) the monolithic structure contains only one FTO substrate, which gives a clear advantage in terms of material cost; (ii) the anode and cathode terminals in the sandwich structure are located on two different substrates, while in monolithic DSSC both terminals are located on the same substrate; and (iii) the sealant in conventional DSSC is typically serve as spacer, whereas in monolithic structure the $\mathrm{ZrO}_{2}$ layer [12] serve as a spacer to separate the $\mathrm{TiO}_{2}$ layer (anode) and counter-electrode side layer (cathode). With the monolithic design, the fabrication process is more adaptable for up scaling because no alignment is necessary when it comes to cell assembly [13]. The photographs of the electrode with carbon and platinum catalyst are shown in Figure 2. Note that the electrodes in this image had not yet undergone dyeing and assembly process, hence the $\mathrm{TiO}_{2}$ was still white in color. Meanwhile, the top-view illustration and the photograph of the constructed monolithic DSSC are 
shown in Figure 3. Although the platinum layer was transparent, the overall cell was opaque due to the nontransparent appearance of $\mathrm{TiO}_{2}, \mathrm{ZrO}_{2}$ and carbon.

In order to ensure that the photoactive component of the cell works perfectly, it is important to characterize the crystal structure of the $\mathrm{TiO}_{2}$ that serves as the host for the light absorbing dye molecules in the working electrode as well as the $\mathrm{ZrO}_{2}$ spacer layer. Figure 4 shows the XRD pattern of the $\mathrm{TiO}_{2}$ single layer and $\mathrm{ZrO}_{2}$ films deposited on top of $\mathrm{TiO}_{2}$. Note that the XRD pattern of non-coated FTO was also displayed to distinguish the corresponding peaks from FTO since the XRD measurements were conducted on samples deposited on top of this conductive substrate. The XRD pattern shows that the $\mathrm{TiO}_{2}$ photoactive layer composed of anatase phase based on JCPDS 21-1272. This was confirmed by the presence of strong peaks located at $2 \theta \sim 25.4^{\circ}$ that can be assigned to (101) plane of anatase titania. Anatase $\mathrm{TiO}_{2}$ is known as one of the common polymorphs of $\mathrm{TiO}_{2}$ that has the highest photoactivity and has slightly higher surface area compared to rutile [14]. The presence of sharp and narrow diffraction peaks indicated that the $\mathrm{TiO}_{2}$ had relatively good crystallinity. High crystallinity is typically associated with high good electron transport as the charge carrier is able to move smoothly between crystal lattices [15]. Therefore, amorphous materials are not preferred as electron transport material in DSSC due to the abundance of defects that will result in high charge recombination rate [16]. Although the degree of crystallinity in this work could not be determined due to the lack of surface area data, the crystal size of the $\mathrm{TiO}_{2}$ crystals could be estimated using Scherrer formula [17]. The crystal size of the anatase $\mathrm{TiO}_{2}$ from the XRD data was determined to be approximately $\sim 30 \quad \mathrm{~nm}$. Meanwhile, from JC-PDS 37-1484, the XRD pattern of the $\mathrm{ZrO}_{2}$ reflective layer only showed monoclinic phase, as indicated by the strong peaks located at $2 \theta \sim 28.1^{\circ}$ and $31.3^{\circ}$. Monoclinic phase is known to be the most naturally occurring form of $\mathrm{ZrO}_{2}$ crystals and is commonly formed below heating temperature of $1100^{\circ} \mathrm{C}$ [18]. Thus, both $\mathrm{TiO}_{2}$ and $\mathrm{ZrO}_{2}$ in the monolithic DSSC fabricated in this work only composed of single crystals. Additionally, the crystal structure of $\mathrm{ZrO}_{2}$ was in the most stable form, indicating that the DSSC fabricated here will be stable enough when subjected to high temperature condition.

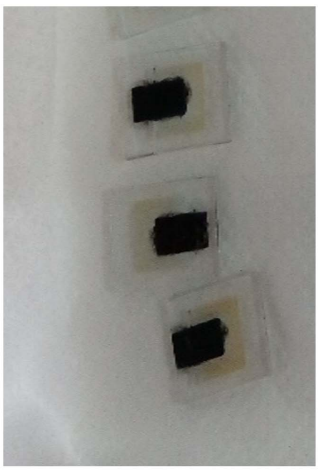

(a)

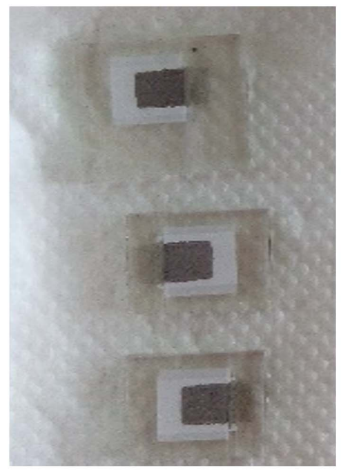

(b)
Figure 2. Photographs of Monolithic Photoelectrode Composed of $\mathrm{TiO}_{2}, \mathrm{ZrO}_{2}$ and (a) Carbon or (b) Platinum as The Catalytic Layer.

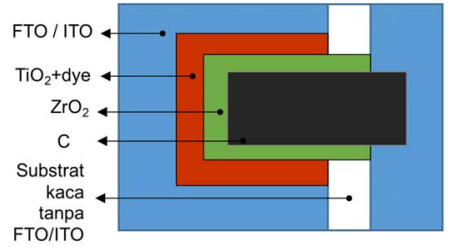

(a)

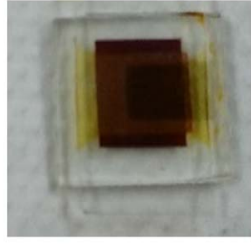

(b)
Figure 3. Top-view (a) Schematic Structure and (b) Photograph of Monolithic DSSC.

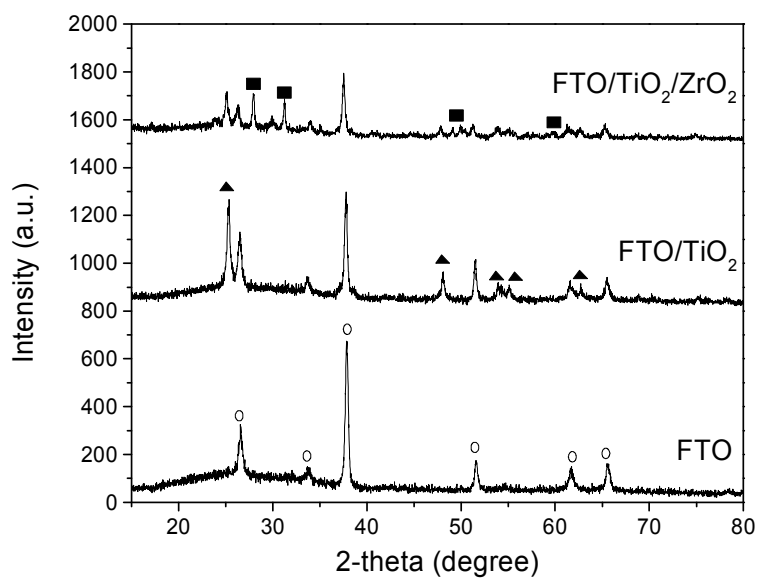

Figure 4. XRD Patterns of FTO, $\mathrm{TiO}_{2}$ and $\mathrm{ZrO}_{2}$. The $\circ$ Symbol Represents The FTO Crystal Planes, The $\boldsymbol{\Delta}$ Symbol Represents The Anatase $\mathrm{TiO}_{2}$ Crystal Planes, while The a Symbol Represents The Monoclinic $\mathrm{ZrO}_{2}$ Crystal Planes. Note that The Intensity Values were Shifted Along The $Y$-Axis for Clarity.

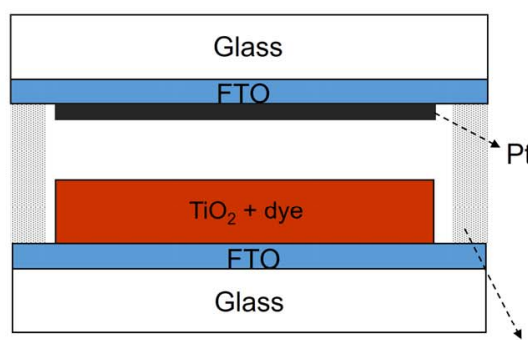

(a)

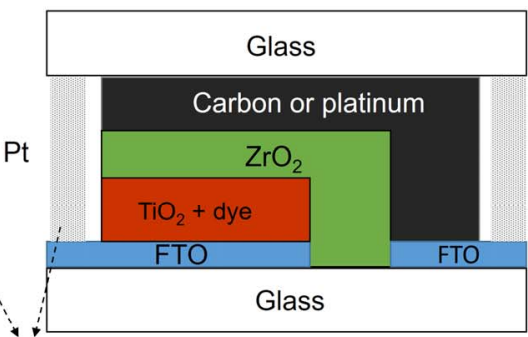

(b)

Figure 1. Schematic Illustration (as Seen from The Side View) of DSSC with (a) Sandwich and (b) Monolithic Structure. 
The surface morphologies of $\mathrm{TiO}_{2}$ photoactive layer, carbon and platinum observed from the SEM are shown in Figure 5. The $\mathrm{TiO}_{2}$ photoactive layers consisted of disordered spherical particles with a size of $\sim 50 \mathrm{~nm}$ and were separated by mesoporous interparticle voids with diameter between 5-50 $\mathrm{nm}$. Mesoporosity typically gives benefit by enhancing the surface area of semiconductors [19]. The particle size of $\mathrm{TiO}_{2}$ was the smallest among the others, wherein the particle size of platinum was two folds larger than that of $\mathrm{TiO}_{2}$. In this case, the largest particle size was possessed by carbon, which existed in aggregates larger than $1 \mu \mathrm{m}$. Small particles existing between the carbon aggregates could possibly be assigned to $\mathrm{TiO}_{2} \mathrm{P} 25$ nanoparticles that were added during the preparation of carbon paste. It should be noted that the addition of P 25 was necessary to increase the adherence of carbon paste onto the substrate and also to avoid film cracking. Additionally, it is also clear that carbon showed better porosity than platinum with much larger voids between the particles. The relatively dense nature of the platinum film could be unfavorable for monolithic DSSC due to the hindering of liquid impregnation. The effect of this will be discussed in the latter section after the photovoltaic characteristics have been presented.

The sheet resistance of carbon and platinum was measured in five different areas using four-point probe system and the results are presented in Table 1 . In a monolithic DSSC, particularly, the catalytic layer holds double function as both catalyst and conductor. The conductivity of the catalytic layer is a crucial parameter because it will affect the charge transport from the counter-electrode to the redox mediators in the electrolyte [1]. The sheet resistance data showed that both carbon and platinum increased the conductivity of FTO glass by at least $3 \Omega /$ sq. Furthermore, carbon showed slightly better conductivity than platinum. Although these results are slightly unexpected considering that platinum is a noble metal, it was suspected that the presence of organic elements within the platinum paste has lowered the conductivity of the platinum. Also, the addition of graphite in the carbon mixture has proven to promote its conductivity. Overall, the sheet resistance data suggested that carbon could be more suitable as catalytic material for monolithic DSSC.

The photocurrent versus photovoltage $(I-V)$ curves of the DSSCs based on carbon and platinum counter electrode are shown Figure 6, while the related photovoltaic parameters obtained during the $I-V$ measurements, including short circuit current density $\left(J_{S C}\right)$, open circuit voltage $\left(V_{O C}\right)$, maximum power $\left(P_{\max }\right)$, series resistance $\left(R_{S}\right)$, shunt resistance $\left(R_{S H}\right)$, fill factor $(F F)$, and photoconversion efficiency $(\eta)$ are listed in Table 2. The efficiency was calculated according to Equation (1):

$$
\eta=\frac{V_{O C} J_{S C} F F}{P_{i n}}
$$

where $P_{\text {in }}$ is the power received from the incident illumination (in watt), which is dependent on the irradiation intensity and the size of the active area. It should also be noted that the values listed in Table 2 were obtained as the average from three replicates for each sample with standard deviation less than $10 \%$.
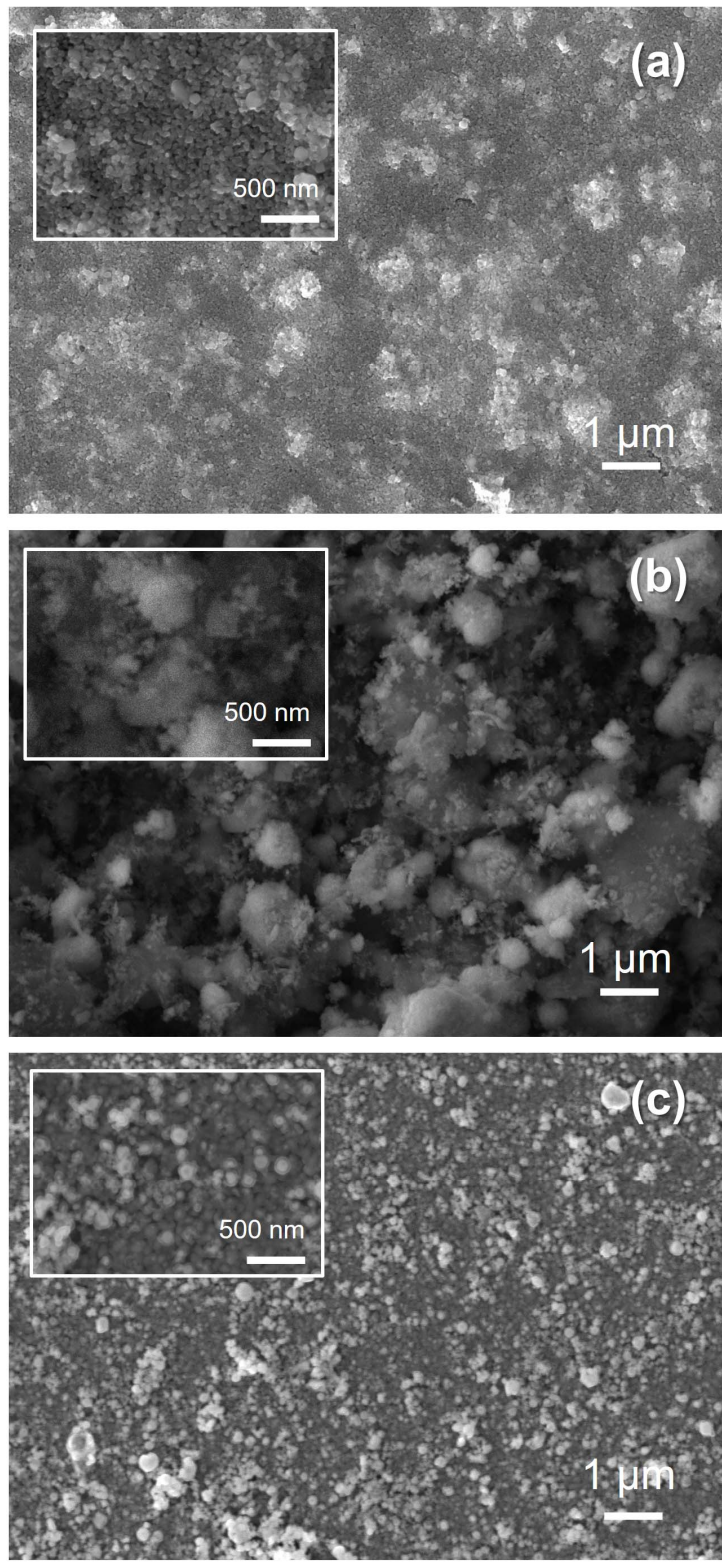

Figure 5. SEM Images Showing The Surface Morphology of (a) $\mathrm{TiO}_{2}$, (b) $\mathrm{C}$ and (c) Pt. Corresponding Images with High Magnification for Each Sample are Shown In The Insets.

TABLE 1

Sheet Resistance Data As Measured using Four-Point Probe

\begin{tabular}{|c|c|c|c|}
\hline \multirow{2}{*}{$\begin{array}{c}\text { Number of } \\
\text { measurements }\end{array}$} & Bare FTO & $\begin{array}{c}|c| \\
\text { Carbon } \\
\text { coated on } \\
\text { FTO }\end{array}$ & $\begin{array}{c}\text { Platinum } \\
\text { coated on } \\
\text { FTO }\end{array}$ \\
\cline { 2 - 4 } & 13.5 & 9.3 & 11.5 \\
\hline 1 & 13.7 & 10.0 & 11.2 \\
\hline 2 & 13.3 & 10.3 & 10.8 \\
\hline 3 & 13.6 & 10.8 & 10.9 \\
\hline 4 & 13.7 & 8.9 & 10.4 \\
\hline 5 & 13.6 & 9.9 & 10.9 \\
\hline Average & & & \\
\hline
\end{tabular}




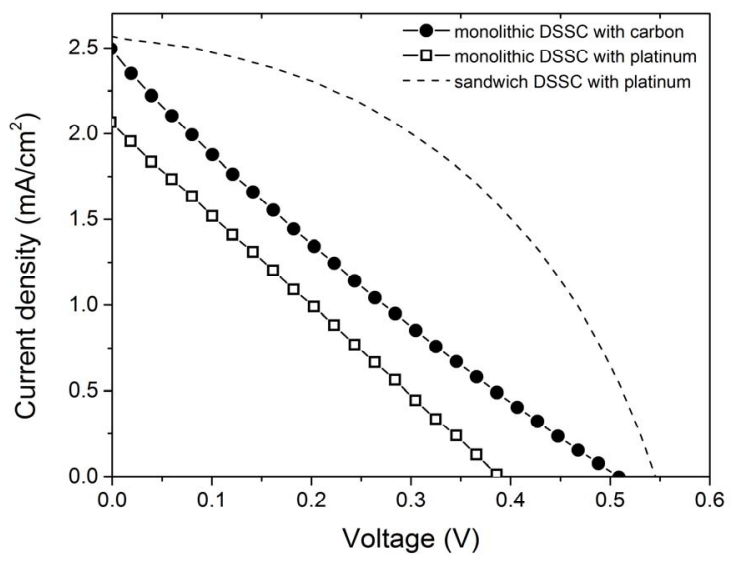

Figure 6. Current-voltage (I-V) Curves of Monolithic DSSC with Different Catalytic Materials as The Counter-Electrode. As a Comparison, The $I-V$ Curve of A Sandwich DSSC is Shown as Dashed Line.

It can be seen from Table 2 that the monolithic DSSC with carbon based counter-electrode exhibited better photovoltaic characteristics than the DSSC with platinum counter-electrode. Despite having slightly lower $F F$, all of the electrical parameters such as $V_{O C}$, $I_{S C}, P_{\max }$, and efficiency of the carbon containing DSSC were higher than those of DSSC with platinum counterelectrode. The value of $V_{O C}$ is related to the charge injection mechanism within the cell. Typically, almost half of the photon energy is loss within the cell due to inefficient regeneration of the oxidized dye [1]. In this case, the lower $V_{O C}$ exhibited by the sample with platinum indicated that the charge transfer between the platinum and electrolyte was not as effective as the injection within the interface between carbon and electrolyte. Although further characterization is required to prove this hypothesis (for example, using electroimpedance spectroscopy), the sheet resistance data as previously shown in Table 1 suggested that our hypothesis could be supported by the fact that carbon showed better conductivity than platinum.

With regard to the $I_{S C}$, it is clear that the photogenerated current produced by the cell in the presence of carbon was far superior compared to that of platinum. Photogenerated current is associated with the

TABLE 2

PHOTOVOLTAIC PARAMETERS OF MONOLITHIC DSSC WITH DIFFERENT COUNTER-ELECTRODE MEASURED UNDER AM 1.5

\begin{tabular}{|c|c|c|}
\hline Parameters & Carbon & Platinum \\
\hline$V_{\max }(\mathrm{V})$ & 0.23 & 0.18 \\
\hline$J_{\max }\left(\mathrm{mA} / \mathrm{cm}^{2}\right)$ & 10.33 & 5.67 \\
\hline$V_{O C}(\mathrm{~V})$ & 0.50 & 0.35 \\
\hline$J_{S C}\left(\mathrm{~mA} / \mathrm{cm}^{2}\right)$ & 2.07 & 1.33 \\
\hline$P_{\max }(\mathrm{W})$ & 2.33 & 1.36 \\
\hline$R_{S}(\mathrm{ohm})$ & $4.10 \times 10^{4}$ & $5.94 \times 10^{4}$ \\
\hline$R_{S H}(\mathrm{ohm})$ & $2.21 \times 10^{4}$ & $1.51 \times 10^{4}$ \\
\hline$F F$ & 0.23 & 0.29 \\
\hline$\eta(\%)$ & 0.019 & 0.011 \\
\hline
\end{tabular}

light absorption ability by the dye molecules. Thus, lower $I_{S C}$ indicated poor dye absorption by the $\mathrm{TiO}_{2}$ working electrode. In the case of monolithic DSSC, the porosity of the spacer and catalytic layer strongly influence the dye impregnation. It is clear that the only distinguished factor in this work was the catalytic layer because the material and processing conditions for the spacer layer were identical. It has already been shown by the SEM images in Figure 5 that the carbon composite materials possessed plenty of open voids between the particles, indicating better porosity than platinum. It was suspected that the porosity factor has affected the infiltration of dye and therefore sample with carbon counter-electrode adsorbed more dye than the sample with platinum, thus giving better light absorbing characteristics.

Overall, the relatively low efficiencies observed on the monolithic DSSC were mainly attributed by the unexpectedly low $F F$. It can be seen in Figure 6 that both of the monolithic DSSCs showed very steep curves that represent poor fill factor. In the contrary, DSSC with double FTO or so-called sandwich structure exhibited better $I-V$ characteristics with $F F>0.5$. Fill factor is strongly related to the internal resistance values, i.e. $R_{S}$ and $R_{S H}$. High $R_{S}$ is typically unfavorable because it gives indication of low carrier movement within the cell and poor contact between semiconductor and the metal contact [20]. In monolithic DSSC, the poor contact between the photoactive area and the FTO electrode is fairly expected due to the planar cell construction. There are several ways that could be done to minimize this problem. First, current collector in the form of metal contact, such as silver tabs, could be added on the external electrodes to enhance the conductivity of the current flow toward the external circuit. Secondly, alternating the thickness of the spacer and counter-electrode could be carried out to obtain the optimized conditions for monolithic type cells. Such studies are currently underway in our project and the results will be published shortly.

\section{CONCLUSION}

Low-cost monolithic type DSSCs have been fabricated on single FTO substrate using platinum and carbon as the counter-electrode. The effects of these catalytic materials on the DSSC performance were investigated. Comparatively, the photovoltaic performance of monolithic DSSC with carbon counterelectrode was better than its opponent, with an average conversion efficiency of $0.019 \%$ and $0.011 \%$ for carbon and platinum, respectively. The better electrical properties exhibited by carbon counter-electrode was partly attributed by its porous nature and better conductivity as revealed by the four-point probe measurement. The present study shows that the infiltration of dye and electrolyte on DSSC with monolithic structure is still a major challenge, which therefore deserves further attention.

\section{ACKNOWLEDGEMENT}

We would like to thank the members of Materials and Devices for Solar Cells research group at the 
Research Center for Electronics and Telecommunication, Indonesian Institute of Sciences (P2ET-LIPI). This research was financially supported by INSINAS Research Grant Program 2017 from the Ministry of Research, Technology and Higher Education of the Republic of Indonesia with a title "Design, Fabrication and Up-scaling of Monolithic Dye-sensitized Solar Modules for Indoor Applications".

\section{REFERENCES}

[1] A. Hagfeldt, G. Boschloo, L. Sun, L. Kloo, and H. Pettersson, "Dye-sensitized solar cell," Chem. Rev., vol. 110, pp. 65956663, 2010.

[2] B. O'Regan and M. Gratzel, "A low-cost, high-efficiency solar cell based on dye-sensitized colloidal $\mathrm{TiO}_{2}$ films," Nature, vol. 353, pp. 737-740, 1991

[3] S. Mathew, A. Yella, P. Gao, R. Humphrey-Baker, B. F. E. Curchod, and N. Ashari-Astani, "Dye-sensitized solar cells with $13 \%$ efficiency achieved through the molecular engineering of porphyrin sensitizers," Nat. Chem., vol. 6, pp. 242-247, 2014.

[4] J. M. Kroon et al., "Nanocrystalline dye-sensitized solar cells having maximum performance," Prog. Photovoltaics Res. Appl., vol. 15, no. 1, pp. 1-18, 2007.

[5] N. M. Nursam, L. M. Pranoto, and J. Hidayat, "Application of Pt Counter-Electrode on TCO-free Substrates for Dye-Sensitized Solar Cells," Jurnal Elektronika dan Telekomunikasi, vol. 12, pp. 70-76, 2012.

[6] T.-L. Zhang, H.-Y. Chen, C.-Y. Su, and D.-B. Kuang, "A novel TCO- and Pt-free counter electrode for high efficiency dyesensitized solar cells," J. Mater. Chem. A, vol. 1, no. 5, pp. 1724-1730, 2013.

[7] D. Li, J. Huang, and R. B. Kaner, "Polyaniline Nanofibers: A Unique Polymer Nanostructure for Versatile Applications," Acc. Chem. Res., vol. 42, no. 1, pp. 135-145, 2009.

[8] J. Xia, L. Chen, and S. Yanagida, "Application of polypyrrole as a counter electrode for a dye-sensitized solar cell," J. Mater Chem., vol. 21, no. 12, pp. 4644-4649, 2011.
[9] S. Kirchmeyer and K. Reuter, "Scientific importance, properties and growing applications of poly(3,4-ethylenedioxythiophene)," J. Mater. Chem., vol. 15, no. 21, pp. 2077-2088, 2005.

[10] L. Vesce et al., "Fabrication of Spacer and Catalytic Layers in Monolithic Dye-Sensitized Solar Cells," IEEE J. Photovoltaics, vol. 3, no. 3, pp. 1004-1011, 2013.

[11] L. Muliani and N. M. Nursam, "Dye-sensitized solar cells based on carbon nanoparticle counter-electrode," Jurnal Teknologi Indonesia, vol. 35, pp. 1-6, 2012.

[12] H. Pettersson and T. Gruszecki, "Long-term stability of lowpower dye-sensitised solar cells prepared by industrial methods," Sol. Energy Mater. Sol. Cells, vol. 70, no. 2, pp. 203-212, 2001.

[13] N. M. Nursam, J. Hidayat, L. Muliani, P. N. Anggraeni, L. Retnaningsih, and N. Idayanti, "From Cell to Module: Fabrication and Long-term Stability of Dye-sensitized Solar Cells," IOP Conference Series: Materials Science and Engineering, vol. 214, no. 1, p. 012007, 2017.

[14] N. G. Park, J. van de Lagemaat, and A. J. Frank, "Comparison of Dye-Sensitized Rutile- and Anatase-Based $\mathrm{TiO}_{2}$ Solar Cells," $J$. Phys. Chem. B, vol. 104, no. 38, pp. 8989-8994, 2000.

[15] J. Yu, J. Fan, and K. Lv, "Anatase $\mathrm{TiO} 2$ nanosheets with exposed (001) facets: improved photoelectric conversion efficiency in dye-sensitized solar cells," Nanoscale, vol. 2, no. 10, pp. 2144-2149, 2010.

[16] B. Ohtani, Y. Ogawa, and S.-i. Nishimoto, "Photocatalytic Activity of Amorphous-Anatase Mixture of Titanium(IV) Oxide Particles Suspended in Aqueous Solutions," J. Phys. Chem. B, vol. 101, no. 19, pp. 3746-3752, 1997.

[17] A. L. Patterson, "The Scherrer Formula for X-Ray Particle Size Determination," Phys. Rev., vol. 56, no. 10, pp. 978-982, 1939.

[18] R. Srinivasan, C. R. Hubbard, O. B. Cavin, and B. H. Davis, "Factors determining the crystal phases of zirconia powders: a new outlook," Chem. Mater., vol. 5, no. 1, pp. 27-31, 1993.

[19] N. M. Nursam, "Porous titania-based composite materials and their high-throughput photocatalytic evaluation for environmental remediation," $\mathrm{PhD}$ thesis, School of Chemistry, University of Melbourne, Australia, 2016.

[20] L. Han, et al., "Improvement of efficiency of dye-sensitized solar cells by reduction of internal resistance," Appl. Phys. Lett., vol. 86 , no. 21 , p. $213501,2005$. 